\title{
Factors resulting in underutilization of pediatric spinal anesthesia in South Punjab (Pakistan)
}

\author{
Haq Dad Durrani, DA, FCPS, MSc ${ }^{1}$, Sairah Sadaf, FCPS ${ }^{2} \bowtie$, Syed Aushtar Abbas Naqvi, FCPS ${ }^{1}$ \\ Amjad Siddique, DA, FCPS ${ }^{2} \bowtie$, Manzoor Hussain Bajwa, DA, FCPS $₫$
}

Author affiliations:

1- Department of Anesthesiology, Pain \& Intensive Care, D. G. Khan Medical College, Dera Ghazi Khan, Pakistan.

2- Department of Anesthesiology \& Intensive Care, Sheikh Zayed Medical College, Rahim Yar Khan, Pakistan.

3- Department of Anesthesiology \& Intensive Care, M. Islam Medical and Dental College, Gujranwala, Pakistan.

Correspondence: Prof. Haq Dad Durrani, Department of Anesthesiology, Pain \& Intensive Care, D. G. Khan Medical College, Dera Ghazi Khan. Pakistan; Phone: +92 3087598502; E-mail: drhaqdad@szmc.edu.pk

\section{Abstract}

Background \& objectives: Spinal anesthesia in children a useful alternative to general anesthesia, is not usually practiced in most of the hospitals of South Punjab. We aimed to evaluate the utilization of spinal anesthesia in children in South Punjab (Pakistan) and to discover the elements preventing its use in children.

Methodology: A questionnaire was delivered to all 47 FCPS qualified anesthesiologists working in South Punjab vide e-mail and whatsapp messages to them. Out of 47 anesthesiologists, 38 (80.85\%) responded. Questionnaire consisted of 3 components. All participants were asked to fill the first component regarding demographic data, but only those who did not administer spinal in children, needed to fill second and third components. In the second component, structured questions with scale 1 to 5 (strongly disagree to strongly agree). In the third component, the participant had open choice to write three most important factors (most important, second most and third most) prohibiting the practice of spinal anesthesia in children.

Results: All of the 47 senior anesthesiologists working in South Punjab were included in this survey. The response rate was $80.85 \%$. Demographic data showed 33/38 (87\%) males and 05/38 (13\%) females, mean age $44.34 \pm 11.06$ yrs, mean of total experience in anesthesia $17.03 \pm 9.12 \mathrm{yrs}$ and mean experience after postgraduation $8.01 \pm 6.85$ yrs. The number of respondents administering spinal anesthesia in children was just $3(7.88 \%)$ and $35(92 \%)$ never used spinal in children. Lack of expertise/training/guidance $(4.69 \pm 0.83)$ is the most common cause prohibiting the use of pediatric spinal anesthesia followed by risk of high/total spinal ( $4.14 \pm 1.31)$, lack of cooperation of child (3.83 $\pm 1.34)$, risk of spinal cord injury ( $3.71 \pm 1.51)$, difficulty in assessment of block ( $3.34 \pm 1.64)$. Less common factors avoiding pediatric spinal include objection by family, objection by surgeon and lack of proper

The number of participants considering lack of expertise/training/guidance most important factors for avoiding spinal anesthesia in children was $9(25.71 \%)$, followed by uncooperative children $8(22.86 \%)$, risk of spinal cord damage $5(14.28 \%)$, risk of high/total spinal $3(8.57 \%)$ and objection by family $3(8.57 \%)$. Other factors quoted were objection by the surgeon, risk of postdural puncture headache, risk of neurological complications, being short duration, not recommended and not acceptable by society.

Conclusion: Pediatric spinal anesthesia is practiced by only three consultants $(7.88 \%)$ in South Punjab out of a total of 47. There is a need to enhance the expertise level of the anesthesiologists during postgraduate training and to remove the fears / phobias attached with this particular practice.

Key words: Pediatric; Anesthesia, Spinal; Barriers; South Punjab

Citation: Durrani HD, Sadaf S, Naqvi SAA, Siddique A, Bajwa MH. Factors resulting in underutilization of pediatric spinal anesthesia in South Punjab (Pakistan). Anaesth. pain intensive care 2020;24(6):622-627; DOI:

10.35975/apic.v24i6.1399

Received: 20 August 2020, Reviewed: 17 October 2020, Revised: 25 October 2020, Accepted: 6 October 2020 


\section{Introduction}

Bainbridge was the first to publish a report of 12 operations on infants and young children under spinal anesthesia. ${ }^{1}$ The technique remained dormant over several decades followed by its resurgence in preterm infants in an attempt to reduce apnea and respiratory insufficiency. Moreover, the Possibility of negative long term effects on exposure to general anesthetics has enhanced interest in pediatric spinal anesthesia. There is a large number of publications reflecting great success of pediatric spinal anesthesia particularly for inguinal herniorrhaphy. ${ }^{2}$

In many situations general anesthesia in children becomes a tricky option. Respiratory tract infections produce bronchial hyperactivity resulting in constriction of smooth muscles in the respiratory tract, which may persist for 6 weeks even after clinical symptoms have disappeared. ${ }^{3}$ On an average six episodes of upper respiratory tract infections occur in children under the age of five. ${ }^{4}$ Peri-operative, stimulation of potentially irritable airways may result in laryngospasm, bronchospasm, desaturation and breath holding. The probability of adverse respiratory events is highest if general anesthesia with endotracheal intubation is administered. 5,6,7

The prevalence of inguinal hernia is higher in premature children. The risks of incarceration, testicular torsion and recurrence of hernia requires early repair of inguinal hernia., ${ }^{8.9}$ There is higher incidence of central apnea, reduced oxygen saturation and bradycardia in prematurely born infants during normal sleep. There is exacerbation of these adverse events after general anesthesia, but not after spinal anesthesia. ${ }^{10}$ Gotum et al. recommended that spinal anesthesia alone or combined with sedation as an alternative to general anesthesia in pediatric patients for lower abdomen and lower extremity operations. ${ }^{11}$

Furthermore, The U.S. Food and Drug Administration (FDA) Safety Communication has warned about the possibility of effect on development of brains of children if they undergo repeated or lengthy use of general anesthetics under 3 yrs of age or third trimester of pregnant women following several experimental studies raising concerns about direct and/or indirect neurotoxic effects of anesthesia. It is also advised to discuss with parents and caregivers about possible complication on brain development and delay of surgery if not expected to affect the health of child. ${ }^{12}$

Pediatric spinal anesthesia, a useful alternative to general anesthesia has been used at our hospital for more than 20 yrs, without any significant problem, but its utilization in South Punjab is scarce $^{13}$. The literature about factors inhibiting utilization of spinal anesthesia in children is scarce.

We aimed to evaluate the utilization of spinal anesthesia in children in South Punjab (Pakistan) and to discover the elements preventing its wide-spread use.

\section{Methodology}

This cross sectional study was conducted after clearance from the Institutional Ethical Committee vide their letter

No. 53/PHY/DGKMC, dated 9 March 2020.

A questionnaire was designed in consultation with consultant anesthesiologists. We carried out a pilot study among eleven expected participants. Reliability of the questionnaire was analyzed by IBM SPSS Statistics 26, the Cronbach's alpha was 0.619. Although usually Cronbach's alpha $\geq 0.7$ is considered to be acceptable. But for a pilot/exploratory study, its value $\geq 0.6$ was considered acceptable. ${ }^{14,15}$

We invited all anesthesiologists with a terminal qualification of FCPS/MD/MS (termed level-III by Pakistan Medical \& Dental Council) working in South Punjab. Name of the participants were kept anonymous. The questionnaires were delivered to anesthesiologists via e-mail and whatsapp. The questionnaire consisted of 3 components. The first component regarding demographic data was to be filled by all of the participants. It required age, gender, total experience in anesthesia, experience after postgraduation, the institute they were associated with, percentage of spinal anesthesia in adults requiring anesthesia and whether they administered spinal in children. The participants, who did not used spinal in children, were asked to fill second and third components. The second component comprised of eight structured questions with numerical scale 1 to 5 . ( 1 denoted 'strongly disagree' and 5 denoted 'strongly agree').

In the third component, the participant had an option to write three most important factors prohibiting them 
Table 1: Demographic Data [Mean \pm SD (Range)]

\begin{tabular}{lc}
\hline \multicolumn{1}{c}{ Variable } & Results \\
\hline Mean age in years & $\begin{array}{c}44.34 \pm 11.06, \\
(29-67)\end{array}$ \\
\hline Number of male participants & $33(86.84)$ \\
\hline Number of female participants & $05(13.16)$ \\
\hline $\begin{array}{l}\text { Mean of Total experience in } \\
\text { anesthesia (yrs) }\end{array}$ & $\begin{array}{c}17.03 \pm 9.12 \\
(5-40)\end{array}$ \\
\hline $\begin{array}{l}\text { Mean of experience in } \\
\text { anesthesia after postgraduation } \\
\text { (yrs) }\end{array}$ & $\begin{array}{c}8.01 \pm 6.85 \\
(10-23)\end{array}$ \\
\hline $\begin{array}{l}\text { Mean of administration of spinal } \\
\text { anesthesia in adults (\%) }\end{array}$ & $\begin{array}{c}59.06 \pm 18.68 \\
(20-90)\end{array}$ \\
\hline $\begin{array}{l}\text { Participants administering spinal } \\
\text { anesthesia in children }\end{array}$ & $3(7.88)$ \\
\hline
\end{tabular}

from administration of pediatric spinal whether included in structured questions or not.

Responses to survey questions were analyzed in IBM SPSS 26 using descriptive statistics and represented as mean \pm standard deviation for quantitative data. Qualitative variables (gender and response of open ended questions) were expressed as percentages and frequencies.
Results: Thirty eight (80.85\%) out of 47 anesthesiologists responded to the questionnaire. Demographic information is given in Table 1.

Our quantitative data reflects that lack of expertise/training/guidance is the most common cause prohibiting anesthesiologist for administering spinal anesthesia in children followed by risk of high /total spinal, lack of cooperation of child, risk of spinal cord injury, difficulty in assessment of block. Less common factors avoiding pediatric, spinal include objection by family, objection by surgeons and lack of proper recommendations (Figure 1).

In response to open ended questions, the largest group of participants considered lack of expertise $(25.71 \%)$ to be the main reason for low use of pediatric spinal anesthesia by the anesthetists. Lack of cooperation by children $8(22.86 \%)$, risk of spinal cord damage 5 $(14.28 \%)$ and risk of high/total spinal $3(8.57 \%)$, objection by family $3(8.57 \%)$ and difficulty in assessment of level of block $2(5.71 \%)$ were considered other most important factors. Objection by the surgeon, risk of postdural puncture headache, neurological complications, meningitis, and not recommended in children were the other reasons mentioned by1 (2.86\%) anesthesiologist (Table 2).

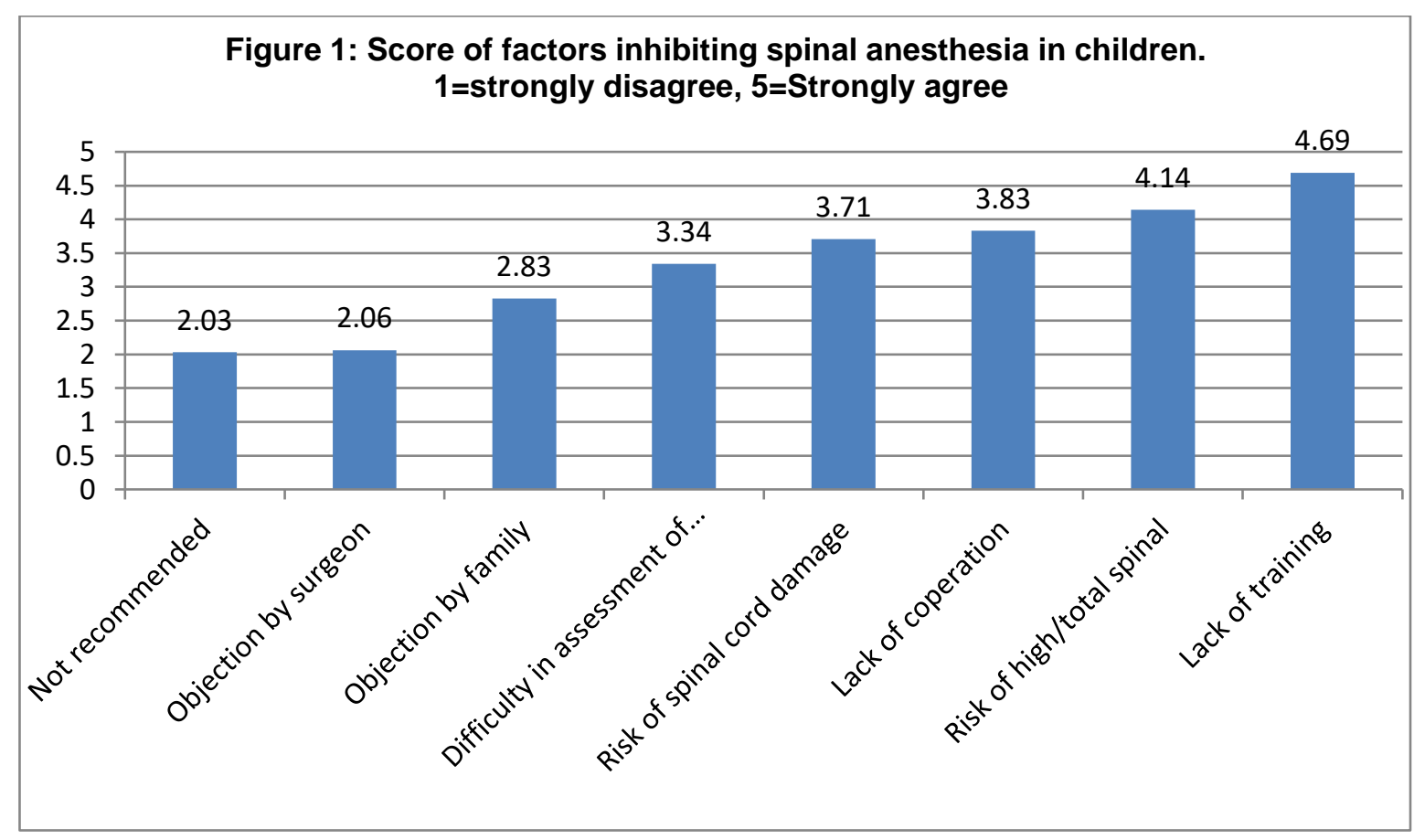


Table 2: Three most common reasons (open ended questions) for not administering spinal anesthesia in children. Data presented as $\mathbf{n}(\%)$

\begin{tabular}{lcccc}
\multicolumn{1}{c|}{ Reasoning } & $\begin{array}{c}\text { Most important } \\
\text { reason }\end{array}$ & $\begin{array}{c}\text { Second most } \\
\text { important reason }\end{array}$ & $\begin{array}{c}\text { Third most } \\
\text { important reason }\end{array}$ \\
\hline Lack of expertise/ training/guidance & $9(25.71)$ & $6(17.14)$ & $5(14.28)$ \\
\hline Risk of high/total spinal & $3(8.57)$ & $12(34.28)$ & $5(14.28)$ \\
\hline Lack of co operation of child & $8(22.86)$ & $6(17.14)$ & $2(5.71)$ \\
\hline Risk of spinal cord damage & $5(14.28)$ & $1(2.86)$ & $7(20)$ \\
\hline Difficulty in assessing block level & $2(5.71)$ & $4(11.43)$ & $4(11.43)$ \\
\hline Family objection & $3(8.57)$ & 0 & $3(8.57)$ \\
\hline Surgeon's objection & $1(2.86)$ & $4(11.43)$ & $1(2.86)$ \\
\hline Meningitis & $1(2.86)$ & $1(2.86)$ & $1(2.86)$ \\
\hline Consider not recommended & $1(2.86)$ & & $1(2.86)$ \\
\hline PDPH & $1(2.86)$ & & $4(11.43)$ \\
\hline Neurological complications & $1 / 35(2.86)$ & $1(2.86)$ \\
\hline Socially not acceptable & & $1(2.86)$ & $1(2.86)$ \\
\hline Local anesthetic toxicity & &
\end{tabular}

\section{Discussion}

Selection of anesthetic technique in children is influenced by several factors including the anesthesiologist's expertise, training, guidance, available facilities and working environment. The literature regarding the prevalence of utilization of pediatric spinal and the elements responsible for its under-utilization is hard to find. However, various researchers have cited some reasons for rare use of this technique.

We selected all the highly qualified anesthesiologists working in South Punjab. Furthermore, our respondents have had a wide experience in anesthesia $(17.03 \pm 9.12$ yrs, varying from 5 to 40 years $)$.

In our study, only three participants $(7.88 \%)$ practiced spinal anesthesia in children, while thirty five $(92.12 \%)$ did never attempt this procedure, although they administered spinal in more than $50 \%$ of adult patients at their institutions. J.C. Sander conducted a survey about pediatric regional anesthesia. The respondents practiced caudal, epidural and peripheral nerve blocks in pediatric. None among them claimed subarachnoid block. ${ }^{16}$ Benjamin $\mathrm{j}$ Walker et al. analyzed that subarachnoid block constituted $2.36 \%$ $(2,034 / 86328)$ of regional anesthesia in children. ${ }^{17}$
Spinal administration is reported as $6.2 \%$ among pediatric regional anesthetic techniques at 261 centers in 33 European countries. ${ }^{18}$

We tried to identify the factors resulting in underutilization of this technique. In our survey, the highest score of $4.69 \pm 0.832$ in quantitative data reflects the lack of expertise/training/guidance as the most important factor. In qualitative data the largest group of anesthesiologists expressed the same observation. This factor was considered the most important by 9 (25.71\%), second most important by $6(17.14 \%)$ and the third most important by 5 (14.28\%) participants, to be the reason for under-utilization of the technique. Administration of spinal by a surgeon to a 4 yrs old child resulted in cardiac arrest. Another report cited the death of a child following spinal anesthesia administered by an anesthetist without proper knowledge and skill. ${ }^{13}$

Second highest score in our quantitative data $4.14 \pm$ 1.309 was given to high/total spinal as a prohibiting factor. In our qualitative data, only 3 (8.57\%) considered it to be the most important but the largest group $12(34.28 \%)$ considered it to be as the second most important reason. Despite the fact that no such survey is published, however, Osazuwa et al. and Gupta et al., cited lack of expertise and risk of high 
spinal as possible causes of avoiding the technique. ${ }^{19,20}$ Lack of cooperation of child has the third highest score in quantitative questionnaire in our study. In qualitative data, it ranked the most important factor as hurdle in the technique. KM Ebert et al. referred spinal anesthesia in children is not popular due to lack of cooperation of children during operative procedure. ${ }^{21}$

Risk of spinal cord damage and neurological complications in children following spinal anesthesia led to its prohibition in a hospital. ${ }^{13}$

Difficulty in assessment of block is another reason with score $3.34 \pm 1.644$. In qualitative analysis, it was ranked at a lower end. Some other authors also mentioned it as a difficulty in evaluation of block, inadequate block, supplemental sedation and need to convert to general anesthesia, a cause of avoiding spinal anesthesia in children..$^{21,22}$

A few participants pointed out short duration of action as compared to adults, reluctance by family and surgeon, transient neurological symptoms, back pain, meningitis, and post dural puncture headache as possible reasons for not choosing spinal anesthesia in children supported by various publications..$^{22,23}$

\section{Limitations}

We only selected anesthesiologists with the highest qualifications, working either in government, semi government or private hospitals of South Punjab. Large scale studies involving anesthesiologists of all grades and all regions of the country are required to address this issue at a national level.

\section{Conclusions}

The practice of pediatric spinal anesthesia is very limited even by the anesthesiologists with the highest qualifications in South Punjab. Lack of adequate training and proper guidance needs to be looked into at postgraduate training and the practice encouraged at national level.

\section{Conflict of interest}

None declared by the authors

\section{Authors' contribution}

HDD - Concept, design and conduct of study SS - Manuscript writing, editing
SAAN - Data collection, statistical analysis

AS - Literature search, manuscript writing

MHB - Manuscript writing, editing

\section{References}

1. Bainbridge WS. A report of twelve operations on infants and young children during spinal anesthesia. Arch Pediatr 1901; 18:570-574. [Google Scholar]

2. AlSuhebani M, Martin DP, Relland LM, Bhalla T, Beebe AC, Whitaker AT, et al. Spinal anesthesia instead of general anesthesia for infants undergoing tendon Achilles lengthening. Local Reg Anesth. 2018 May 3;11:25-29. [PubMed] DOI: 10.2147/LRA.S157650

3. Bösenberg The child with a runny nose! Upper respiratory tract infection in children: impact on anesthesia. South Afr J Anaesth Analg 2007;13(2):3335. DOI: $10.1080 / 22201173.2007 .10872472$

4. S. Megan Grelson. Risk of complications using laryngeal mask airway versus endotracheal tube during general anesthesia in pediatric patients with upper respiratory infections: a narrative review. Creation of the upper respiratory infection screening ToolC and management Al. Anesthesia e J, 1 (1) (2013) [Free full $\underline{\text { text] }}$

5. Mamie C, Habre W, Delhumeau C, Argiroffo CB, Morabia $A$. Incidence and risk factors of perioperative respiratory adverse events in children undergoing elective surgery. Paediatr Anaesth. 2004 Mar;14(3):218-24. [PubMed] DOI: 10.1111/j.1460$\underline{9592.2004 .01169 . x}$

6. Hamilton ND, Hegarty M, Calder A, Erb TO, von Ungern-Sternberg BS. Does topical lidocaine before tracheal intubation attenuate airway responses in children? An observational audit. Paediatr Anaesth. 2012 Apr;22(4):345-50. [PubMed] DOI: 10.1111/j.14609592.2011.03772.x

7. Fortuna A. Caudal analgesia: a simple and safe technique in pediatric surgery. $\mathrm{Br} J$ Anaesth. 1967;39:165-170. [PubMed] DOI: 10.1093/bja/39.2.165

8. Uemura S, Woodward AA, Amerena R, Drew J. Early repair of inguinal hernia in premature babies. Pediatr Surg Int. 1999;15(1):36-9. [PubMed] DOI: 1007/s003830050507

9. Vaos G, Gardikis S, Kambouri K, Sigalas I, Kourakis G, Petoussis G. Optimal timing for repair of an inguinal hernia in premature infants. Pediatr Surg Int. 2010;26(4), 379-85. [PubMed] DOI: 1007/s00383-0102573-x

10. Krane EJ, Haberkern CM, Jacobson LE. Postoperative apnea, bradycardia, and oxygen desaturation in 
formerly premature infants: prospective comparison of spinal and general anesthesia. Anesth Analg 1995 Jan 1;80(1):7-13. [PubMed] DOI: 10.1097/00000539199501000-00003

11. Gotum Sn, Acharya S, Bajracharya Gr, Hyoju S. Efficacy and safety of spinal aneshesia between 3 to 14 years for infraumbilicus surgery. Nepal Med Col J 2019 ;21[2]:147-52.

12. US Food and Drug Administration. FDA Drug Safety Communication: FDA review results in new warnings about using general anesthetics and sedation drugs in young children and pregnant women. 2017-02-05]. https://www. fda. gov/drugs/drugsafety/ucm532356. htm. 2017 May 20.

13. Durrani HD. Pediatric spinal anesthesia at DG Khan (Pakistan); Our experience of 20 years. Anaesthesia, Pain \& Intensive Care. 2020 May 7;24(1):115-.

14. Hamed Taherdoost. Validity and Reliability of the Research Instrument; How to Test the Validation of a Questionnaire/Survey in a Research. International Journal of Academic Research in Management (IJARM), 2016, 5. ffhal-02546799f.

15. Bolarinwa OA. Principles and methods of validity and reliability testing of questionnaires used in social and health science researches. Niger Postgrad Med J. 2015 Oct-Dec;22(4):195-201. [PubMed] DOI: 10.4103/11171936.173959

16. Sanders JC. Paediatric regional anaesthesia, a survey of practice in the United Kingdom. Br J Anaesth. 2002 Nov;89(5):707-10. [PubMed]

17. Walker BJ, Long JB, Sathyamoorthy M, Birstler J, Wolf $\mathrm{C}$, Bosenberg AT, et al. Complications in Pediatric
Regional Anesthesia. An Analysis of More than 100,000Blocks from the Pediatric Regional Anesthesia Network. Anesthesiology: 2018 Oct 1;129(4):721-32. [PubMed] DOI: 10.1097/ALN.0000000000002372

18. Dadure C, Veyckemans F, Bringuier S, Habre W. Epidemiology of regional anesthesia in children: Lessons learned from the European Multi-Institutional Study APRICOT. Pediatric Anesthesia. 2019 Nov;29(11):1128-35.

[PubMed] DOI: 10.1111/pan.13741

19. Osazuwa $\mathbb{H}$, Charles OI. Spinal anaesthesia in paediatric orthopaedic services: A five year experience in a Nigeria hospital. Sahel Medical Journal. 2019 Apr 1;22(2):92. [PubMed]

20. Gupta A, Saha U. Spinal anesthesia in children: A review. J Anaesthesiol Clin Pharmacol. 2014 Jan;30(1):10-8. [PubMed] DOI: 10.4103/0970$\underline{9185.125687}$

21. Ebert KM, Jayanthi VR, Alpert SA, Ching CB, DaJusta DG, Fuchs ME, McLeod DJ, Whitaker EE. Benefits of spinal anesthesia for urologic surgery in the youngest of patients. J Pediatr Urol. 2019 Feb;15(1):49.e1-49.e5. [PubMed] DOI: 10.1016/i.jpurol.2018.08.011

22. Sola C, Hertz L, Bringuier S, De La Arena P, Macq C, Deziel-Malouin S, et al. Spinal anaesthesia in neonates and infants: what about the cerebral oxygen saturation? Br J Anaesth. 2017 Nov 1;119(5):964-971. [PubMed] DOI: $10.1093 / \mathrm{bja} / \mathrm{aex} 218$

23. López T, Sánchez FJ, Garzón JC, Muriel C. Spinal anesthesia in pediatric patients. Minerva anestesiologica. 2012 Jan 1;78(1):78. [PubMed] DOI: $10.1111 / j .1460-9592.2011 .03769 . x$ 